\title{
SIMULATION MODELING OF BARREL BORE WEAR UNDER DYNAMIC PRESSURE LOAD
}

\begin{abstract}
Wear is one of the major forms of material deterioration, often limiting both the life and the performance of the industrial components and requiring frequent replacement of the components. Wear is a very complex process and occurs by combination of several factors, such as the type of lubrication, loading speed, temperature materials, surface finishing and hardness. To simulate wear as a whole is very difficult, in many cases even not possible. The simulation by using the finite element method (FEM) is becoming increasingly popular and accessible. The FEM can also be used by solving mechanical wear, where it is critical to know the right way and method for arriving to the correct results. The method for obtaining additions of wear in the paper is developed on the base of previous practice, which used the combination of finite-element models and external algorithm for calculating wear. A FEM program ABAQUS has been used in this paper. The additions of degradation were obtained from an own developed script from MATLAB software, which is used to calculate selected equations and specific outputs in ABAQUS.
\end{abstract}

Keywords: Gun barrel bore dynamics, wear of materials, finite element method, pressure load.

\section{Introduction}

The presence of wear has been known for several millennia. Wear is one of the major forms of material deterioration, often limiting both life and performance of the industrial components. This phenomenon has not been fully explained till today. This is an unavoidable effect. Wear is affected by a variety of conditions, such us the type of lubrication, loading, speed, temperature, materials, surface finish and hardness. For example, nitrided steels are widely used due to their superior hardness and attractive surface hardness, fatigue life and tribological properties [1]. The prediction of wear is therefore an important part in mechanical engineering. The degradation of surfaces is not always an undesirable factor. Sometimes surface degradation is desired, for example a pencil drawing on paper, where the soft graphite is damaged. It is also desired by processing of materials, because without abrasion it is not possible to polish steel to the required surface roughness. Nevertheless, if the process of wear is known for a long time, the scientific studies of wear are relatively new. Consequently there are a few theories about wear not always the same.

Because of the complexity of the wear process, there are still lacks to fully understand the wear behavior. It is very difficult directly to observe wear in contact of two moving bodies. Experiments must rely on the results and observations made after individual tests and then causes of wear can be considered.

There are two methods for grading of wear. The first are the conditions under which the wear occurs. It is, for example, the presence of lubricant, or solid abrasive particles. The second method is to choose one of the four operating mechanisms which were developed by Lim and Ashby [2]. These are seizing, melting, oxidation and plasticity. Plasticity is classified as the mechanical wear area.

The finite element method is known to be an effective numerical tool for the solution of boundary value problems on complex domains [3, 4 and 5]. Today, FEM methods are used for the analysis of every major engineering design and probably in every branch of scientific studies. The method is now used primarily through the application of commercial finite element programs ABAQUS, ANSYS, AUTODYN, etc. These programs are used on mainframes, workstations and PCs and are employed to solve very complex problems.

The main task of the FEM in the wear calculations is to compute the fields of contact stresses [6 and 7]. The elements of different type and shape with complex loads and boundary conditions can be used simultaneously. The method for

\footnotetext{
* ${ }^{1}$ Milan Zmindak, ${ }^{1}$ Zoran Pelagic, ${ }^{2}$ Martin Nagel, ${ }^{3}$ Lukas Smetanka, ${ }^{1}$ Zuzana Stankovicova

${ }^{1}$ Department of Applied Mechanics, Faculty of Mechanical Engineering University of Zilina, Slovakia

${ }^{2}$ DJH Engineering Center, INC., Martin, Slovakia

${ }^{3}$ Department of Transport and Handling Machines, Faculty of Mechanical Engineering University of Zilina, Slovakia

E-mail: milan.zmindak@fstroj.uniza.sk
} 
obtaining additions of wear in this paper is developed on the base of previous practice, which used the combination of finiteelement models and external algorithm for calculating wear. These practices were mainly from the works of Berabdallah and Olender [8].

The additions of degradation were obtained from an own developed script from MATLAB software, which is used to calculate selected equations from Lim and Ashby and specific outputs in FEM software ABAQUS.

\section{The current state of modeling of shot dynamics}

In modern times we get to the forefront of simulating of various processes in a wide spectrum of disciplines. Studying the dynamics of weapons is no exception. Experiments are often replaced by simulations to simplify and accelerate the acquisition of required results for research and customers. Every problem can have unmistakable properties, different initial and boundary conditions, various material properties, types or the load application. Making experiments in tasks with high number of variations is very expensive and timeconsuming, which is in these times unfavorable for anyone. The FEM models allow assembling parametric tasks where it is possible to fast and effectively change the geometry, material properties, boundary conditions and loading, while the only cost is the computing time of numerical solution. Simulations of shooting are very complex; where it is often needed to take into account many simplifications. Therefore, it is necessary to compare the results of simulations with the results of experimental measurements. The FEM is using either modal or direct integration techniques. Given the complexity of the task, the way of direct integration with explicit numerical schemes is recommended [9].

Wear is divided into six types: adhesion, fatigue, abrasive, vibration, cavity and erosive. The mechanism of wear can be understood as a dynamic action, which is dependent on many parameters and on the prediction of the problem, defined as the initial value of the problem. Wear in general can be defined in the form of equation as:

$\frac{d h}{d s}=f$ (load, velocity, temperature, material properties,

where $h$ represents the depth of wear and s represents the length of traveled path. Many wear models exist; their mathematic expressions differ from simple empiric relationship to difficult equation dependent on physical definition [10]. Parameters and coefficients are usable only for one solved task in many cases. Only few of them can be used to verify wear in practice. The most widely used model for linear wear is defined by an equation where the rate of wear is proportional to normal load
$\tilde{Q}=K \tilde{p}$

where $\tilde{Q}$ is the rate of wear, $\mathrm{K}$ the coefficient of wear and $\tilde{p}$ is the normalized pressure. This equation is described in literature as the Archard law of wear, despite its basic form was published by Holm [11] expressed as

$\frac{V}{S}=K \frac{F_{N}}{H}$

where represents the volume of wear, $F_{N}$ normal force and $H$ is the hardness of material. The wear coefficient $K$ was introduced to better represent the agreement of simulation and experiment. According to Holm, it expresses the number of abraded atoms in mutual contact. According to Archard, it's the probability, that by mutual interaction of surface roughness particles of wear are created. The value of this coefficient should be obtained by an experiment and it is always lower than 1 .

The depth of wear - $h$ has a deeper meaning for engineering practice. Archard subtracted the contact surface $A$ and obtained the equation

$\frac{V}{A s}=\frac{h}{s}=k p$

where $k$ is dimensional wear coefficient $\left(\mathrm{Pa}^{-1}\right)$ and $p$ is the normal contact pressure $(\mathrm{Pa})$. For linear wear of delamination we can write the expression

$\frac{d h}{d s}=k p$

Expanding eq. (2) by adding the influence of temperature we obtain [12]

$\tilde{Q}_{\text {melt }}=\frac{\left(T_{\text {melt }}-T_{0}\right) H}{T^{*} L_{\text {melt }} \beta \tilde{v}}\left(\alpha_{12} f_{F r} \tilde{p} \tilde{v} \frac{T^{*} \beta}{T_{\text {melt }}-T_{0}}\right)$

where $T_{\text {melt }}$ is the melting temperature, $T_{0}$ is the ambient temperature, $T^{*}$ represents the equivalent to melting temperature for steel, $f_{F r}$ is the friction coefficient, $\alpha_{12}$ and $\beta$ represent constants, $L_{\text {melt }}$ is latent heat of steel melting and is the normalized speed.

\subsection{Requirements on the model}

Simulating shot dynamics by using parametrical models should be closest to reality, so the results can give good insight for different types of ammunition (displacement, velocity etc.). The current research is considered with these conditions [13]:

Precise geometry of the model: the weapon is composed of many parts, which are in contact with each other. Friction is also included in the model. 
Shaped contact: is between projectile and segment created by notches. The segment carries motion through shaped contact on the projectile due to pressure of flue gases.

Explosion: is replaced with pressure load, which is applied to the barrel bore, segments, the grenade and on the tail fins. The area where the pressure load is applied is changing with time. Depending on the phase it is increasing or decreasing.

The damping mechanism depending on the weapon type is either a spring or hydraulic. Using the hydraulic concept the simulation is extended by the prescribed recoil force. For springs the recoil force function is the immediate recoil force.

The cylindricity of the barrel: the model must contain disorders because the barrel is not perfectly direct.

\section{The models of weapon wear}

An internal ballistics environment of weapon causes complications in experimental analysis. Therefore, the FEM is used to analyze the problem. The wear of the barrel bore is a complex task, therefore the analytical modeling is aimed on particular problems on a smaller scale. The approaches that can predict wear are empirical and computational [12 and 14].

The flowchart of the wear module is shown in Fig. 1.

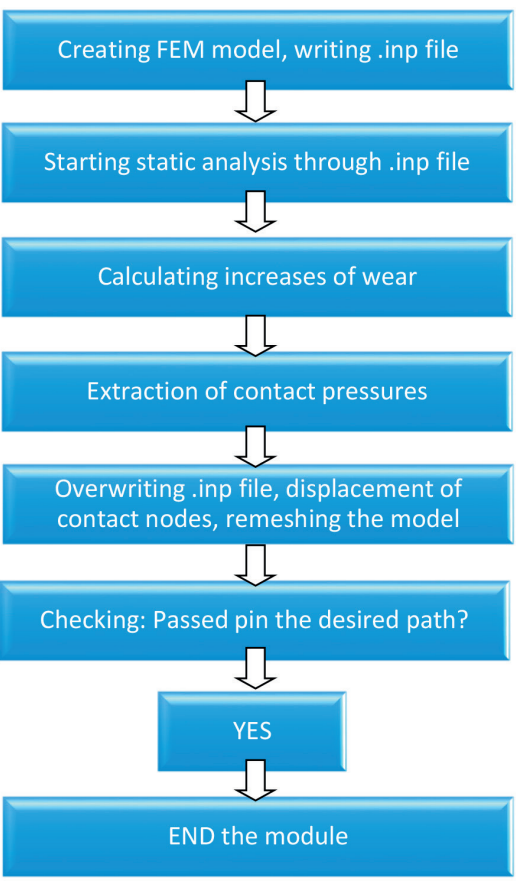

Fig. 1 Flowchart of the wear module

The script was made in the mathematical software MATLAB. In the first step the script starts the analysis in ABAQUS through background MATLAB on the base of the input file (*.inp) which was created to model the assembly.
For the solution of wear we need the contact pressures in selected nodes from the results. The script subsequently waits for the completion of the analysis. In the second step an output data file is processed so that it can be overwritten. In the third step the script calculates the corresponding increases of wear on the base of the selected equation of wear by Lim and Ashby. The values of increases assigns to the positions in the $\mathrm{Y}$ axis. The whole model is fitted from the contact area, therefore it needs to be re-meshed to the original contact position. The last step represents the cycle, which either starts the next simulation, or, depending on the total distance, ends the simulation process. During the computational process the computed increments of wear are displayed.

\section{Transient analysis the dynamics of shot}

For modeling the whole assembly of shooting from a barrel, all functional parts must be created and added to the simulation, in our case it is the housing with complete damping mechanism (hydraulic or spring), barrel inlayed to housing, bullet formed penetrator overlaid segments of the guide ring, wherein the segments are associated with a sealing ring. For our calculations it is sufficient to make a simplified 2D axis-symmetric assembly model consisting of $125 \mathrm{~mm}$ smooth tank barrel T-72, guide ring and of anti-tank warhead APFDS BM-15 penetrator.

\subsection{Mesh}

In areas where high pressures are anticipated there are smooth elements which are increased in the outward direction to save computational memory. The smallest elements have the size of $1 \times 1 \mathrm{~mm}$ and they consist of regular bilinear elements. The transient areas were made up of triangles; they were used to increase magnification with elements through two layers of the size $4 \times 4 \mathrm{~mm}$. FEM model of the assembly is described in Fig. 2 and detailed view of the mesh is shown in Fig. 3.

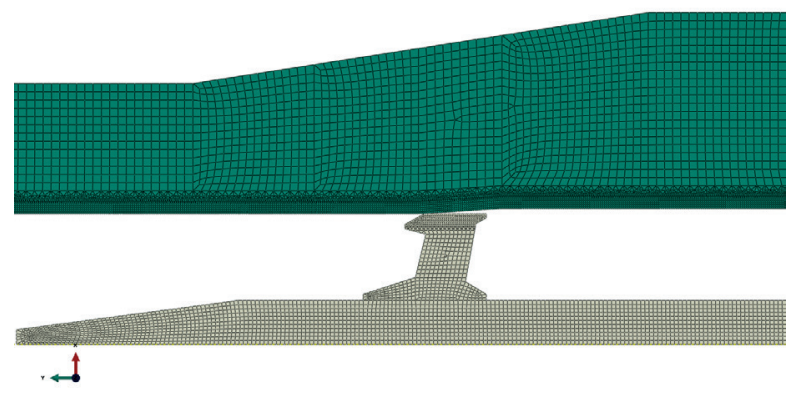

Fig. 2 FEM model of the assembly 


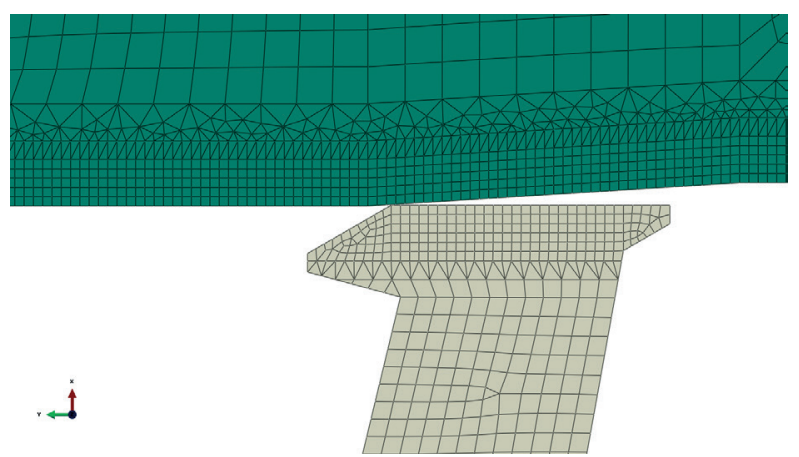

Fig. 3 Detailed view of the mesh

\subsection{Materials}

All the considered materials behave as elastoplastic materials. The barrel material is similar to steel STN 16540 and it is stronger compared with the material of the guiding ring, which is similar to steel STN 16240 . The mechanical properties of used material are given in Table 1 .

Material properties of used materials

Table 1

\begin{tabular}{|l|c|c|c|c|c|}
\hline & $E[\mathrm{MPa}]$ & $\mu[-]$ & $\rho\left[\mathrm{kg} \cdot \mathrm{mm}^{-3}\right]$ & $\mathrm{R}_{\mathrm{e}}[\mathrm{MPa}]$ & $\mathrm{R}_{\mathrm{m}}[\mathrm{MPa}]$ \\
\hline Barrel & 210000 & 0.3 & $7.84 .10^{-6}$ & 1185 & 1488 \\
\hline Segment & 210000 & 0.3 & $7.84 .10^{-6}$ & 600 & 894 \\
\hline
\end{tabular}

\subsection{Boundary conditions and loading}

By real shot from a tank the barrel is present during the process in several mutual contact areas. These are the teeth penetrators with segments, the segments with guiding ring and tank barrel. The single parts were necessary to simplify and therefore only the contact between the segment and barrel bore was ultimately considered. The friction coefficient between steels is 0.8 . The boundary conditions for the idealized case and referred to as direct loading are shown in Fig. 4.

\subsection{Results of the wear barrel bore module}

In view of the amount of data the computational times of each cycle were different. For each area the complete analysis time was 30 cycles. One cycle was considered as one shot. The development of wear in the first examined area is described in Fig. 5. The graph in Fig. 6 shows details of history of the first shot.



Fig. 5 Evaluation of wear in the contact surface during shots (area behind the transition cone)

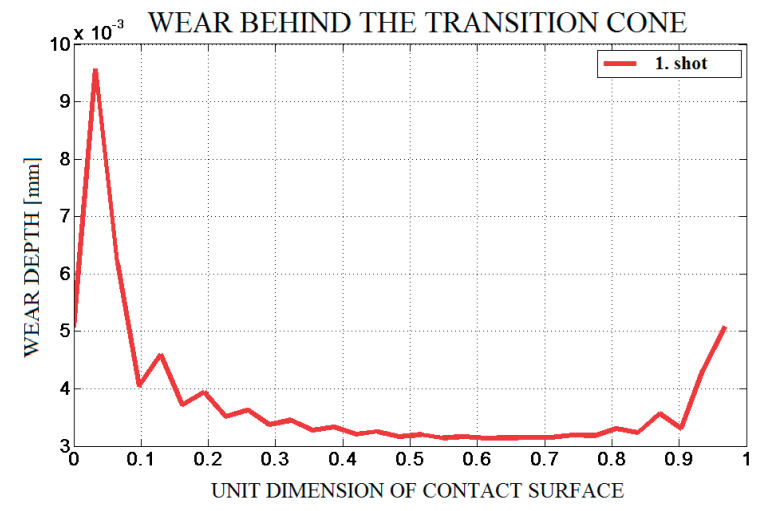

Fig. 6 Detail of wear in the contact surface after first shot

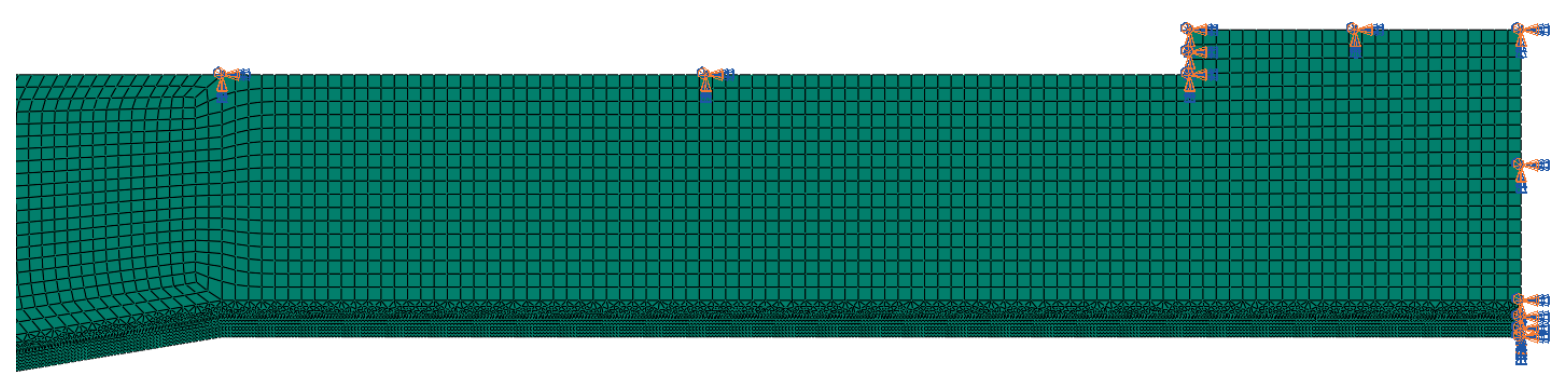

Fig. 4 Boundary conditions applied on the surface of the barrel 
The value of maximal wear after 30 shots is around 0.13 $\mu \mathrm{m}$. From the graph it is clear that the wear grows faster in the contact are with the leading edge. The maximal deviations of the barrel bore wear are actually on its end, therefore the load applied on the leading edge should be disregarded.

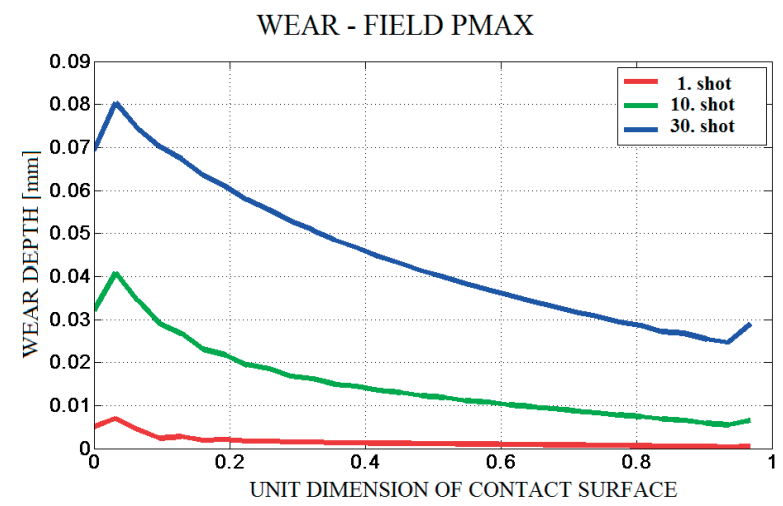

Fig. 7 Evaluation of wear on the contact surface in the field $P_{\max }$



Fig. 8 Evaluation of wear on the contact surface in the field $V_{\max }$

Figures 7 and 8 describe increases of wear in $P_{\max }$ and $V_{\max }$ fields. From these graphs it is clear that the more shots are fired from the chamber the less wear is on the barrel.
On the base of the obtained results the module was made which simulated the wear on examined areas by using a simplified FEM model of T- 72tank barrel bore. The module of calculation of wear used the equation (6). The minimal wear for areas 1, 2 and 3 amounted after 30 cycles the values 130,80 and $18 \mu \mathrm{m}$ as it is shown in the previous figures.

\section{Conclusion}

In this paper an algorithm for wear calculation is presented. The algorithm uses simple equation based on the delamination wear formulation with the combination with commercial FE code ABAQUS. The paper has shown on an example that it is possible to simulate wear of materials using interface coupling of a MATLAB code and commercial software to calculate the stresses needed as input data for the wear module. The main objective of this work was to extend the possibilities of the ABAQUS program and to include the possibility of modeling wear in dynamical analysis by including also some factors as temperature. This will increase the possibility of modeling of wear processes using ABAQUS or a similar FE software.

A two dimensional FE model of a barrel bore consisting of the barrel and a shot segment was modeled. The model was used to show wear depth through time at various distances, in this case the distance was considered in shot times. The results show the decreasing of wear depth with the time steps (shots). The contours have a good agreement with results presented in literature, and can be also verified experimentally.

\section{Acknowledgement}

The authors gratefully acknowledge the support of the Slovak Grant Agency VEGA 1/0983/15.

\section{References}

[1] YANG, Z., NORTHWOOD, D. O., SUN. X., LUMBRERAS, R., BARBER, G. C., ZOU, Q.: The use Nitriding to Enhance Wear Resistance of Cast Iron. In: De Hosson, J. Th., M., Brebbia, C. A. (eds.), Surface effects and contact mechanics XI, Wit Press, 2013, pp. 171-182.

[2] LIM, S. C., ASHBY, M. F.: Wear Mechanism Maps. Acta Metall., 35(1):1-24. 1987.

[3] BUCALEM, M. L., BATHE, K. J.: The Mechanics of Solids and Structures - Hierarchical Modeling and the Finite Element Solution. Springer, 2011.

[4] BATHE, K. J.: Frontiers in Finite Element Procedures \& Applications - Chap. 1. In: Computational Methods for Engineering Technology. B. H. V. Topping and P. Ivanyi (eds.), Saxe-Coburg Publications, Stirlingshire, U.K., 2014.

[5] ZMINDAK, M., MIKUSIK, J., KLIMKO, J.: Dynamical Rolling Contact Stress Analysis of Cylindrical Roller Bearings using FEM. Proc. of the 10 Intern. Conference on Vibration Problems 2011, Liberec, 2011. 


\section{COMMNICOIIONS}

[6] HANDRIK. M., VASKO, M., KOPAS, P., SAGA, M.: Effective Finite Element Solution and Post-processing for Wide Load Spectrum. Communications - Scientific Letters of the University of Zilina, vol. 3A, 2014, pp. 19-26.

[7] MUKRAS, S., KIM, N. H., SAWYER, W. G., JACKSON, D. B., GERGUIST, L. W.: Numerical Integration Schemes and Parallel Computation for Wear Prediction Using Finite Element Method, Wear, 266, 2009, pp. 822-831.

[8] BENABDAllah, H., OLENDER, D: Finite Element Simulation of the Wear of Polyoxymethylene in Pin-On-Disk Configuration, Wear 261, 2006, pp. 1213-1224.

[9] ECHES, N., COSSON, D., LAMBERT, Q., LANGLET, A., RENARD, J.: Modelling of the Dynamics of a $40 \mathrm{~mm}$ Gun and Ammunition System during Firing. $7^{\text {th }}$ European LS-DYNA Conference, 2009.

[10] MENG, H-C.: Wear Modelling: Evaluation and Categorisation of Wear Models. Dissertation, University of Michigan, 1994.

[11] HOLM, R.: Electric Contacts. Uppsala : Almqvist and Wiksells Boktryckeri AB, 1946.

[12] PODRA, P., ANDERSSON, S.: Simulating Sliding Wear with Finite Element Method, Tribology International, 32, 1999, 71-81.

[13] JOHNSTON, I. A. Understanding and Predicting Gun Barrel Erosion, Weapons Systems Division, 2005.

[14] RABINOWICZ, E.: Friction and Wear of Metals, John Wiley \& Sons : New York, 1995. 